\title{
Washington Poison Center as Perceived by Our State's Emergency Physicians
}

\author{
William O. Robertson, MD, Angela Caffrey, MD
}

Washington Poison Center

\begin{abstract}
Introduction: In 1986, we conducted the first survey of Washington emergency physicians about their perceptions of the performance of the Washington Poison Center (WPC); the results were summarized and published. The exercise was repeated in 1993, 1997 and in 2005.

Methods: The original conventional 2-page survey was updated and distributed with an explanatory letter and return envelope to a mailing list obtained from the state chapter of the American College of Emergency Physicians. Responses were tallied, summarized and compared to prior surveys.

Results: For 2005, 612 surveys were distributed; 221 were returned. The average respondent had been in practice for 14 years, with more than 50\% functioning in "urban" communities. They reported calling the WPC an average of 19 times per year, and particularly valued being able to consult with a board-certified medical toxicologist in a virtually "STAT" manner. In more than 80\% of calls, the information played a positive role in management of the patient.

Conclusions: Washington's emergency physicians continue to highly value the WPC's services, with increasing numbers in favor of governmental support of the operation.
\end{abstract}

\section{INTRODUCTION}

In 1986, as part of the Seattle Poison Center's Quality Assurance/ Improvement' Program, we instituted our first satisfaction survey of our state's emergency physicians to complement one we had conducted previously with our state's pediatricians. The president of the state chapter of the College of Emergency Physicians cosigned the cover letter appealing for responses, resulting in a $>54 \%$ response rate. The study was replicated in 1993 and 1997, with the latter as part of a University of Washington medical student's research thesis project. With the burgeoning of visits to hospital emergency departments and the availability of online Poisindex in so many of the state's hospitals $(>80 \%)$, we were curious if our role has changed in the minds of "emergency physician consumers."

\section{MATERIALS AND METHODS}

The survey form was updated, and a listing of 612 functioning emergency physicians ( $>400$ members of Washington's state chapter of the College of Emergency Physicians) was prepared by the chapter's secretary. A survey form with an invitation to reply and a stamped self-addressed return envelope were mailed to each physician; one follow-up mailing was sent to non-responders after 30 days. The state chapter's local office oversaw the administrative arrangements and mailed us the completed forms, which

Keywords: hypercalcemia, verapamil, calcium channel blocker toxicity, dialysis

Notes: There was no outside funding of any kind used for this study.

Corresponding Author: Dr. William O. Robertson, MD, Washington Poison Center, 155 NE 100th Street, Seattle, WA 98125. Phone: 206-5172356. Email: mryuk@wapc.org 
were tallied at the Washington Poison Center. When the results were analyzed and a summary report completed, highlights were mailed out as a part of the College of Emergency Physicians chapter's monthly e-mail newsletter-again at no cost to the Poison Center.

\section{RESULTS}

Of the 612 mailed surveys, 221 (36\%) were completed and returned. The average respondent had been in an urban practice for 14 years and called the Center an average of 19 times per year, with more than $50 \%$ of the calls being directed to the medical toxicologist on call. Many indicated that they used Micromedex's Poisindex in their own hospital for diagnostic and treatment information, particularly for determining ingredient data.

Respondents valued our emergency treatment measures most; second was access to other ingredient data, particularly rumors about what was "on the street" or had recently left it. The wide variety of acute signs and symptoms was third on the list, followed by treatment guidelines and finally long-term effects. As in the past, a third of the respondents were not sure of the professional status of the Poison Center staff who answered their calls, despite our efforts to educate that they are specially trained pharmacists, nurses, EMTs, paramedics, and related health professionals.

From our vantage point, the most important result was that $97 \%$ gave the Poison Center a $>80 \%$ satisfaction rating for the information provided and the manner in which it was transmitted-up slightly from previous years. However, the emergency physicians felt that we could still do more with occupational and environmental issues, even though they make up less than $5 \%$ of our calls. (As an aside, these two topics occupy $>50 \%$ of the material we insert in our own quarterly publication "Washington Poison Network" and in columns or paragraphs we provide to newsletters of other professional organizations across the state.)

Finally, and for the first time, the respondents felt that the information that the Poison Center and medical toxicologists provided played a positive role in managing $>80 \%$ of the patients involved. We were also astonished to note that $>70 \%$ of the respondents were of the opinion that the state or the federal government should be the sole support of the nation's network of poison centers-a dramatic change from 6 years previously.

\section{DISCUSSION}

We are convinced that this effort has provided us much helpful information and that the process has alerted the state's emergency physicians about our continued existence, our enhanced role as the "Chemical Information Center" for the state with reference to bioterrorism and homeland security issues, and our commitment to responding to our users' wants and needs. Poison centers have been on the scene for more than 50 years; our relationships with our users are critical in giving us guidance regarding how to prepare for the next half century-even to the extent of outsourcing our calls to private and electronically equipped homes in the future. Clearly, the accidental exposures in toddlers are far more manageable today than they were in the past, but the challenge of environmental chemicals and their costs and benefits is even more complicated today than it was a decade ago. Application of scientific principles proved so helpful with toddlers' issues that we plan to continue that approach in coping with environmental chemicals.

\section{CONCLUSION}

Our fourth survey of our state's emergency physicians over the past 20 years continues to provide us and the physicians with helpful information about coping with today's and tomorrow's toxicologic challenges. We urge other centers to consider using such an approach.

The authors have no potential financial conflicts of interest to report.

\section{REFERENCES}

1. Caffrey A, Robertson WO. Emergency Physicians Opinions Re: Washington Poison Center. J Toxicol/Clin Toxicol 2005;43(6);771.

2. Haulman J, Misra S, Robertson WO. Washington ER Physicians Perceptions of Poison Centers. Vet and Human Tox 1993 Apr;35(2):164-165. 